\title{
EL PAISAJE COMO CUERPO VIVIDO EN LAS CRÓNICAS DE JOSÉ DONOSO ${ }^{1}$
}

\author{
Andrés Ferrada Aguilar \\ Universidad de Playa Ancha, Valparaíso, Chile/ Universidad de Chile, \\ Santiago de Chile, Chile \\ aferrada@upla.cl
}

RESUMEN/ ABSTRACT

Este trabajo aborda la construcción del paisaje urbano en "cuerpo vivido" en una selección de crónicas y fragmentos de diarios de José Donoso. Considerando enfoques contemporáneos al paisaje en diálogo con las reflexiones del escritor, se advierte un espacio literario desde el cual emerge un paisaje subjetivado y afectivo que se sobrepone al contexto político y social de la ciudad de Santiago en la década del ochenta. Articulado desde una relación corporal e imaginativa con la ciudad, que implica un juego de proximidad y lejanía, este paisaje corrobora la fisonomía literaria en las crónicas de Donoso.

Palabras Clave: José Donoso, paisaje urbano, cuerpo vivido, espacio literario, crónica.

\section{LandSCAPE in PRESENT Body IN THE CHRONICLES OF José DoNoso}

This article explores the constitution of an urban landscape in "present body" in a selection of chronicles and notes from diaries by José Donoso. Considering contemporary approaches to landscape, as well as the author's own reflections, this work draws attention to a literary space where an affective landscape arises that confronts the dominant political context in the city of Santiago in the 1980s. Articulated from a corporeal and imaginative relation with the city, which implies a play on proximity and distance, this landscape confirms the literary design in Donoso's chronicles.

1 Este artículo se enmarca en el Proyecto FONDECYT de Iniciación № 11150158 , "Las crónicas de José Donoso y la enunciación de Santiago a través del paisaje urbano", del cual soy investigador responsable. 
KEYWORDS: José Donoso, urban landscape, integrated body, literary space, chronicle.

Recepción: 27/04/2017

Aprobación: 03/07/2017

\section{INTRODUCCIÓN}

Con su retorno a Chile en 1981, José Donoso (1924-1996) confirma in situ el temor gestado desde el extranjero a un país asolado por la dictadura. Desde España imagina un reencuentro con la ciudad de Santiago; hay planes y proyectos, pero también, y en mayor grado, incertidumbre y desconfianza. En sus crónicas y diarios, las reflexiones constituyen una bitácora del retorno, indispensable para esclarecer su relación con la ciudad en un momento crítico. Por un lado, el autor percibe el menoscabo de las prácticas urbanas en el contexto de una dictadura cívico-militar. Por otro, surge una gradual politización de la escritura que, según el autor, contradice el oficio literario y el fundamento estético de la obra de arte. En una nota de sus diarios de 1979, año marcado por la muerte de su padre, escribe: "Imposible que vaya a Chile. Me postra, por ahora, esta alternativa tan desesperada del regreso. Las pérdidas. Dolor. Ausencia. Cambios constantes de ciudad, estado, país" (Pilar Donoso 228).

A partir de esta enunciación preliminar, ex situ, de Santiago, se aprecia la emergencia de un paisaje que incide en la fisonomía de la ciudad referencial y literaria en la escritura de Donoso. Enfoques geográficos, arquitectónicos y urbanísticos debaten la constitución epistemológica del paisaje y su lugar en la cultura occidental moderna. Las miradas que confluyen en su escrutinio, desde las estéticas visuales pasando por la historia del arte y los géneros referenciales, añaden a la compleja condición del paisaje una cartografía de saberes heterogéneos. Sin ignorar los rasgos que observan las disciplinas mencionadas, el paisaje urbano en las crónicas de José Donoso dialoga con un espacio literario y con imaginarios que acentúan el cuerpo político y estético de la ciudad.

Urbanas en cuanto a la narración de un espacio-tiempo citadino, las crónicas de este estudio tematizan el retorno del escritor a Santiago de Chile después de veinte años de residencia en el extranjero. Sus diarios personales también dan cuenta de la crisis que provoca este traslado. En una anotación del 19 de octubre de 1979, Donoso se pregunta: “¿Qué haría en Chile? Por 
un lado me emociona, por el otro, el lado negativo, me aterra y me ahoga" (Pilar Donoso 230). Entre otras cosas, le amenaza la "imposibilidad de elegir una máscara de anonimato, como en el extranjero, cualquier máscara que me guste y que hago cursar como válida [...]" (231). La experiencia del retorno incide en la percepción desalentada de la ciudad, en la visualización de un paisaje urbano y, desde luego, en una escritura ensayística que dibuja con acierto una crítica de la vida cotidiana. Las crónicas “Tener y no tener" (1980), "El retorno del nativo" (1981), "El espacio literario" (1986) y "Los barrios bajos de Santiago" (1982) dialogan con fragmentos de diarios personales de José Donoso ${ }^{2}$ en la Firestone Library, Manuscripts Division, Universidad de Princeton, y Correr el tupido velo (2009) de Pilar Donoso. Las crónicas mencionadas se encuentran reunidas en Artículos de incierta necesidad (1998) y José Donoso: Diarios, ensayos, crónicas (2009).

Nuestra hipótesis establece que la construcción de un paisaje urbano en el espacio de las crónicas de José Donoso obedece a la intervención en "cuerpo vivido" de un sujeto afectivo. Este sujeto, que al mismo tiempo autoriza y narra la crónica, recorre los espacios sensible e imaginativamente, alentado a cada paso la fantasía del enmascaramiento a fin de resistir el "contexto político-económico-social" (Artículos 207) que se impone sobre Santiago. Así, y desde una relación corporal con la urbe no solamente vivida, sino también vívida en su tesitura literaria, las crónicas del retorno ofrecen un paisaje que se sobrepone a la uniformidad de los referentes. El paisaje urbano surge a partir de una relación sensible con la ciudad que refleja la mirada perpleja del autor en tres instancias de enunciación interrelacionadas: desde el extranjero, con una aproximación ex situ al paisaje chileno, luego cuando el cronista se reincorpora desorientado a su ciudad natal, y finalmente cuando las impresiones de este reencuentro se diseminan en el corpus de la escritura.

La diversidad de significados que adopta el paisaje sigue de cerca la evolución del espacio en el pensamiento occidental como categoría epistémica. Entendido como sustrato mítico, el espacio genera la habitación colectiva del mundo en una épica fundacional y política. Ejemplo de lo anterior es el diseño de las ciudades latinoamericanas, liderado por una voluntad de conquista que "borra todo trazo cultural para imponer una creación ex nihilo [...] en una praxis de la violencia dominadora en la esfera del imperio de los signos" (Guerra 45). Será a partir de la fenomenología cuando el espacio 
ocupe un lugar privilegiado en la experiencia individual del sujeto. Desde otro ángulo, Henri Lefebvre confirma que el espacio está supeditado no solo a "representaciones abstractas (metafísicas)" (73), o a la conceptuación ideológica de las prácticas sociales, sino que se realiza, en efecto, a través de una producción material. Michel De Certeau, en tanto, advierte en el espacio urbano el dominio de estrategias que encuentran resistencia en infinitesimales tácticas carentes de un "lugar propio" (50).

La modulación paisajista del espacio nos remite a la experiencia de "cuerpo vivido" que sugiere el filósofo francés Jean-Marc Besse, y cuyos antecedentes se encuentran en el ensayo El hombre y la tierra (1952) del geógrafo Eric Dardel. Según este último, la actividad geográfica debiese estar unida a una "pregunta ontológica que concierne al hombre donde encuentra finalmente su sentido verdadero" (Besse 155). Esta inflexión comporta un ethos humanista que lee el espacio estética y culturalmente, dejando entrever un sesgo paisajista. "La geometría opera sobre un espacio abstracto", advierte Dardel. "El espacio geográfico tiene un horizonte, un modelado, color, densidad. Es sólido, líquido o aéreo, ancho o estrecho: limita y resiste" (Cit. en Besse 157). En los estudios de Besse sobre paisaje esta "geograficidad humana" conlleva "el movimiento, pero también la tensión que se despliegan entre un aquí y un allá, entre una base y un horizonte, a priori fundamentales propios de cualquier tipo de existencia humana" ("Espacio" 8, énfasis del texto). A partir de esta valoración apreciamos la figura de un sujeto "afectivo" que participa de una "dimensión polisensorial presente en las experiencias paisajísticas, desde una perspectiva del cuerpo vivido" (Besse, "Espacio" 4). Sobre este punto, Besse insiste que "el paisaje exige un cuerpo de carne, una mirada encarnada, un ojo vivo, en otros términos, un ímpetu, una intencionalidad que atraviesa el espacio que se abre entre lo cerca y lo lejos" (Sombra 166).

Estudiar el paisaje urbano significa reconocer la porosidad y dispersión de una "urbanicidad hecha de coexistencias no totalizables"3 (Nancy, Ciudad 78). Intervienen así fugas excéntricas que desafían la totalidad de una concepción

3 Con el término "urbanicidad" Jean-Luc Nancy signa fenómenos inasibles en la ciudad contemporánea. "Urbanidad", en tanto, sugiere un "supuesto refinamiento de costumbres citadinas" (78). Este refinamiento busca, por ejemplo, mediatizar el contacto del sujeto con los espacios urbanos. Dicha urbanidad jugaría así en contra de un paisaje "palpado" directamente por la proximidad física del sujeto. 
cartesiana del paisaje, como las fenomenologías espaciales y los imaginarios ${ }^{4}$. Los enfoques contemporáneos al paisaje advierten dos condiciones que éste habría gozado antes de su interpretación iluminista: fluidez y dinamismo. Esta apertura genera una confluencia donde la visualidad se integra a otros regímenes perceptuales. A diferencia de otros fenómenos, los paisajes contradicen leyes de comprobación, incluso tratándose de tipologías paisajistas. Promueven, en cambio, modulaciones donde "lo imaginario, los proyectos y proyecciones, los símbolos y las utopías" (Lefebvre 72) sustituyen la interpretación sistémica del espacio. La ocurrencia del paisaje dependerá así de figuraciones estéticas y sociales en constante proceso de resignificación. Variable y movedizo, este enfoque revela la disposición afectiva que interviene en el paisaje urbano. En su etimología latina, affectus revela la voluntad de incidir en y "afectar" aquello que habita fuera del sujeto. Subyace, tanto en el paisaje como en los afectos, una inclinación que estimula, también, el placer de dominio. Pagus sugiere, sin ir más lejos y entre otras acepciones, la administración económica de un territorio.

Sobre este punto, el crítico de estética Raffaele Milani clarifica: "Mientras el territorio es una expresión geográfica, política y social, el paisaje conserva significados simbólicos y afectivos" (46). Por su parte, el arquitecto e historiador de arte Javier Maderuelo concibe el espacio de la ciudad "como un lugar que, al ser capaz de provocar sensaciones estéticas y sentimientos afectivos, reclama la capacidad de ser interpretado como "paisaje"” (576). El sociólogo estadounidense Richard Sennett sigue una dirección similar, señalando que la "geografía de la ciudad moderna" (24), a través de metonimias y metáforas, evidencia conflictos "enraizados en la sociedad occidental al concebir espacios para el cuerpo humano en los que los cuerpos son conscientes unos de otros" (24). Las crónicas de José Donoso, en tanto, indican la presencia de sujetos confrontados con una urbe "sin alma y sin voz" (Artículos 159) y tensionan, por lo tanto, asimetrías entre el cuerpo anhelante del cronista y el cuerpo silente de la ciudad.

\footnotetext{
Entendidos como "elaboraciones simbólicas de lo que observamos o nos atemoriza o desearíamos que existiera" (García Canclini 154), los imaginarios urbanos aportan, como el género mismo de la crónica, figuraciones de lo inabarcable. Desde este supuesto, nuestro estudio acentúa el potencial creativo de los imaginarios que, sin totalizar, construyen imaginariamente la ciudad a partir de una percepción tensionada por la incertidumbre. Esta tensión no dejará de asistir el modo en que José Donoso percibe y elabora los paisajes urbanos en sus crónicas.
} 
Destaco a continuación trabajos relevantes que han abordado el espacio y el paisaje en las obras de Donoso desde esferas interdisciplinarias. En su introducción a Cartografía de José Donoso (2004), Pablo Catalán señala que las novelas del autor acentúan la "continuidad entre el espacio textual y el espacio real [...], produciendo el efecto de diferencia por medio del cual se constituye la dimensión estética" (14). Esta observación encarece grados de convergencia entre referencialidad y arte escritural y, desde aquí, imbricaciones espaciales y narrativas. En José Donoso: paisajes, rutas y fugas (2015), Sebastián Schoennenbeck ofrece un enfoque al paisaje a partir de elementos visuales en Casa de campo. Advierte una tendencia a "naturalizar" el paisaje, "cuando en realidad es una construcción cultural cuya materia prima, por decirlo así, es la naturaleza" (71). Nuestro estudio, por su parte, remite el paisaje a una cultura urbana o segunda naturaleza, y a un espacio literario que revela la mirada desconcertada de Donoso en circunstancias críticas de enunciación. La experiencia del retorno y la incapacidad de asimilar los cambios en la ciudad de Santiago se suman a "esa melancolía definitiva cuando uno pasa los sesenta y comienza a contar, a contar los años, y todos los días es un arqueo de lo que uno no es" (Donoso, Diarios 501).

Cuando Donoso discute el espacio literario en una crónica homónima de 1986, el énfasis recae en el ámbito novelístico, “donde no sólo los personajes se mueven y respiran, sino donde medra la emoción del autor" (Artículos 115). Sobresale en su aproximación, sin embargo, un acento en la creación de visiones parciales y subjetivas que rige no solo su producción narrativa, sino también cronística. En este sentido, las ciudades en la escritura donosiana se enuncian afectivamente y "poseen una vocación que consiste en generar idiomas capaces de relatar la historicidad y corporalidad de espacios [...] silenciados" (Ferrada, "Articulación" 120). Hemos sugerido que el paisaje urbano encuentra en los intersticios estéticos de la escritura una segunda transformación. De este modo, el espacio literario se gesta y solidariza con una construcción paisajística. Así, una encrucijada que estimula el presente estudio advierte las complicidades entre el espacio literario y el paisajista, entendidos como relieves en una poética de artificio y abstracción. Este trabajo intentará, en consecuencia, visualizar la emergencia de un paisaje urbano doblemente abstraído, tanto de su territorio referencial como de la normatividad de una "oligarquía contemporánea" que busca gobernar la ciudad bajo un signo museístico (Donoso, Artículos 206). 


\section{MIRADAS EX SITU AL PAISAJE CHILENO}

Rosalba Campra estima que "cuando la realidad europea se convierte en la única posible, el 'allá' latinoamericano, abandonado por necesidad, es reconocido -y elegido- como único espacio propio, en la afirmación de un regreso futuro" (91). El conflicto de una pertenencia dividida no se resuelve con el retorno. Por el contrario, se inicia la readaptación a un espacio que se percibe transformado y ajeno, aun en las rutinas cotidianas. En la crónica "Tener y no tener" (1980), Donoso señala, desde Madrid, que su regreso a Chile se tensiona ante "la idea de abandonar Europa con su riqueza de sugerencias históricas y culturales [...] para ir en busca de un paisaje virgen pero que puede estar ya depredado, como lo está la costa española, por ejemplo" (Artículos 77). Antes, el autor ha comparado la deforestación madrileña con la Santa Inquisición, "como si fuera pecaminoso que algo viviente adquiriera su forma natural" (76). Desde esta latitud, Donoso siente que en Chile aún se conserva un apego por los paisajes y su patrimonio. "Una casa con un modesto pilar de esquina, una iglesia de adobe blanqueado de hace no mucho, el parrón decimonónico de un convento, el estudio de la flora y de la fauna, la restauración cuidadosa de los escasísimos monumentos históricos, es una característica de nuestra gente" (78).

Confluyen en esta composición construcciones rurales y urbanas en un imaginario híbrido del país natal. La esquina, como la calle, condiciona trayectorias citadinas. El adobe y el parrón, en cambio, indican lugares comunes privilegiados en la construcción del paisaje campestre del valle central. Atraviesa este imaginario, también, un orden, una noción de la "sociedad chilena conformada inicialmente en el siglo XIX con materiales coloniales, sobre un molde de modernidad burguesa de carácter oligárquico" (Morales, Muertos 96). El país se evoca desde España, en una perspectiva que encarece el valor patrimonial de los elementos constitutivos del paisaje, es decir "nuestra gente" y los hitos que originan la culturización de la naturaleza. Importa señalar que en esta crónica la lejanía geográfica no es solo una coordenada de enunciación, sino un tema que problematiza la percepción ex situ del paisaje chileno.

En la misma crónica Donoso recuerda su traslado de la casa en calle Constanza, hoy Avenida Holanda en Providencia, a la calle Ejército en el centro de Santiago. Indica "que si bien en Ejército vivían casi exclusivamente familias que la mía 'ubicaba', como se decía en aquel tiempo, y aunque en la superficie tuviera un empaque más urbano, seguía siendo una calle muy 
cerca del agro y del siglo diecinueve con su pachorra siestera y el paso [...] de una señora Edwards con sus Boston terriers negros como murciélagos, para pasearlos en la vecina Plaza Ercilla" (71). Como en la mirada a Santiago desde Madrid, prevalece en esta escena un cruce de tiempos donde lo tradicional convive con una belle époque criolla ${ }^{5}$. Ambos pasajes alteran la lucidez espacio-temporal del pensamiento racionalista, según el cual el progreso histórico supone la metódica superación de etapas precedentes. La advertencia de esta ruptura influye en la percepción de un paisaje discontinuo encarnado en la memoria del cronista y, por lo tanto, en constante estado de transformación.

“Tener y no tener" destaca así como preámbulo en la enunciación del paisaje urbano santiaguino. Su contexto de producción, la residencia en el extranjero y la proximidad del retorno a Chile, también altera uno de los supuestos en la conformación del paisaje. El pacto entre el entorno y el "cuerpo vivido", como señala Besse, deja de orientar la constitución paisajista en al menos dos sentidos. Por un lado, la percepción incipiente de un "paisaje virgen que puede estar ya depredado" (77) es fruto de una conjetura que espera confirmación. Por otro, esta configuración insta, a través de un sujeto exiliado, un enfoque comparado al paisaje donde intervienen señas cosmopolitas y transatlánticas. A diferencia del despliegue in situ del paisaje en "El retorno del nativo", la paciencia del cuerpo en "Tener y no tener" crea un bosquejo contemplativo en el que la mirada se cruza con la imaginación del paisaje. El ámbito especular nos remite en esta crónica a una visión interior que percibe la ciudad desde una lejanía, "aportando otra claridad, un conocimiento [...] adquirido y repartido mediante algo parecido a sistemas nerviosos alternativos que producen una lucidez distinta" (Diarios 337). Del mismo modo, los dispositivos que abstraen el paisaje del territorio circundante -miradores, umbrales y la propia escritura de la crónica desde España-favorecen un perspectivismo vinculado a la subjetividad del cronista.

$5 \quad$ La imagen del país desde el extranjero es análoga a la casa paterna en la escritura de José Donoso. Ambos espacios integran la presencia de una tradición rural y una vocación urbana. Conjeturas sobre la memoria de mi tribu (1996), por ejemplo, acentúa el hogar de su infancia, inmune al deterioro de la modernidad. En El jardín de al lado (1981) y La desesperanza (1986), en tanto, el recuerdo espejeado del país y la casa paterna semeja una poética espacial contraria a las voluntades de poder. Como en las crónicas del corpus, en estos casos el paisaje urbano se hace visible desde una zona "distante" -la casa real, imaginada o representada- que instancia la experiencia de habitar la ciudad en "cuerpo vivido". 
En este sentido, las reflexiones de Donoso divagan sin apremios de consumación. Este tránsito, por cierto, no busca satisfacer la apertura discursiva de la crónica. Acentúa, más bien, una consciencia de sí mismo y de la escritura como sitio de interrogación. "He seguido con un apasionamiento que ha sido criticado, las huellas de aquellos que de un modo o de otro han configurado mi sensibilidad, huellas en que es tan rico este continente que abandono. Allá tiene que haber equivalencias, otras opciones" (78), afirma el autor. La subjetividad parece sostenerse en la trayectoria fluctuante de la migración, anticipando los recorridos del cuerpo en la construcción paisajista de Santiago. El autor habla desde un aquí madrileño que evoca el país natal, un "allá" que sugiere dilación geográfica y espaciamiento. El deíctico cumple su función, pero resulta más eficaz como índice de un país y un paisaje que habitan la memoria del cronista. La crónica donosiana insiste así en un diseño literario y biográfico que compite con la materialidad de los referentes.

La obra narrativa de José Donoso destaca el carácter arbitrario y contingente del sujeto en consonancia con una idea fuerza en su escritura. "Yo no sé qué es eso de la autenticidad", expresa en uno de sus diarios. "Lo que sí creo es que la vida humana consiste en un refinado y complejísimo sistema de enmascaramientos y simulaciones" (Cit. en Pilar Donoso 38). Sus crónicas también despliegan un sujeto biográfico que se enmascara, o deviene otro, a través del paisaje. La simulación, por un lado, y la construcción distanciada del paisaje, por otro, confirman un "estar fuera", una mediación geo-biográfica que contribuye al surgimiento del paisaje urbano. Esta distancia alienta un reencuentro promisorio con el paisaje natal, pero al mismo tiempo sitúa al autor frente a disyuntivas e incertidumbres.

Quizás, piensa, el paisaje que conoció se encuentre ya "depredado", como la costa española, que "ya murió, prostituida, vendida, anulada, degradada" (77). Estos términos, que destacan una progresiva reificación del paisaje, aparecen nuevamente en crónicas posteriores, esta vez como rasgos asociados a la ciudad de Santiago. Detrás de esta incisiva evaluación subyace no solo un estado de cosas, o una crítica que indica la derrota de una vitalidad, sino también un anhelo de restauración. Por otro lado, Donoso conoce bien los pliegues estéticos del paisaje, como parte del tejido escritural y experiencia que altera su relación con los objetos sensibles. Al inicio de "Tener y no tener" distingue los atributos formales de la Villa Serbelloni, una "sofisticada flor de mármoles y cristal que brota en los jardines cuidadosamente preservados donde, en la época del Emperador Vespasiano, Plinio el Viejo escribió su Historia Natural" (74). Interesa notar que la villa conforma un diseño paisajista 
que deviene artificio mimético, semejante a una "sofisticada flor". Luego, en un giro retórico de falsa modestia, el autor se excusa: "Me he alargado en esta introducción -que no es mi tema- porque el ambiente es espectacular" (75). ¿Cuál sería, entonces, el tema de esta crónica si no la celebración de una persistencia encarnada en el artificio paisajista de una villa italiana, en contraposición con aquello que desaparece bajo una obscena y degradante voluntad económica?

Guardando diferencias, la degradación de la costa española es análoga a la depredación del paisaje chileno. La precariedad de ambos espacios revela la disyunción entre la modernización urbana y la geografía del territorio. “¿Es tan inevitable todo esto?”, se pregunta Donoso. “¿O es cuestión de cuidado, de cariño, de las duras virtudes de la pobreza?” (78). Destaca en esta reflexión una austeridad alerta al agotamiento de los recursos, contrapuesta a un progreso naturalizado como destino infalible. En esta dirección, la disyuntiva entre "tener y no tener" apunta no solo a la disponibilidad de bienes simbólicos -“sugerencias históricas y culturales", las llama el autor-que dejan entrever, al otro lado del Atlántico, un paisaje degradado. Indica, más allá de los valores de un grupo o clase, cómo Donoso expresa una consciencia de finitud que en sus diarios asocia a su propio aislamiento. "No puedo 'enchufarme' a la red eléctrica que es este país", escribe el 19 de agosto de 1981, ya de regreso en Chile. "[E]stoy afuera de la gente, que desconozco, afuera de la intimidad de Santiago Barrio Alto (lo demás es otro mundo, impenetrable para mí) y lo que he visto de paisaje -la costa, la cordillera que rodea a Santiago, no es suficiente para motivarme. Estoy seco" (Cuaderno 53).

El contacto con los paisajes constituye un modo de interpretar el espacio que opera en dirección opuesta a la desaparición. Cada uno de sus recorridos por Europa asegura al autor un sentido de permanencia porque allí encuentra, como en otras latitudes, registros urbanos, paisajistas y literarios que configuran su sensibilidad (77). Entre otros, destacan "los estudios trascendentales en Ballagio, Rilke caminando por el Hotel de los Ingleses en Ronda, el sitio donde Raskolnikov besó la tierra desde San Petersburgo, el Mont Saint Victoire" (77). Aun así, en un gesto interrogativo del Yo cronístico, sobreviene la incertidumbre: “¿Abundarán por mucho tiempo más estas sugerencias?" (77). En la siguiente parte veremos la condición de estas sugerencias y el lugar que ocupan en la percepción in situ del paisaje urbano santiaguino. 


\section{EL CUERPO IN SITU Y LA EMERGENCIA ESCRITURAL DEL PAISAJE URBANO}

Si en "Tener y no tener" el paisaje se evoca en la memoria de un sujeto desde el extranjero, en "El retorno del nativo" el cuerpo del narrador y la ciudad intercambian sus saberes in situ. Una consecuencia de esta cercanía es, por cierto, el giro del acto enunciativo que, acentuando el recuerdo y la nostalgia en un primer momento, se desliza a la comprobación de las tesis que el autor sostiene desde Europa. Se advierte una transición que va desde la conjetura a la confirmación y que, sin embargo, no prefigura necesariamente una síntesis. La relación del autor con la ciudad de Santiago evade resoluciones nítidas. Encarece, en afinidad con una divagación conjetural, decursos que se prestan más bien al juego dialéctico y al enmascaramiento que a las partidas cerradas. Para Donoso, imaginar las ciudades significa "viajarlas" con entusiasmo y asombro renovados, aun si se trata de lugares frecuentemente visitados. Su objetivo será deshabituar la percepción del entorno inmediato. Sobre este aspecto, en sus talleres literarios subraya la función transformativa del viaje, señalando que "el contacto prolongado con otras tierras y otras culturas, sin duda relativiza todo lo de aquí, y al relativizarlo, aunque uno escriba sobre lo más íntimamente chileno, sobre lo más doméstico, va a darle forzosamente una dimensión universal" (Cit. en Pilar Donoso 407).

Una postura similar adopta en su aproximación a los paisajes, que motivan el despliegue de la subjetividad inquisitiva del cronista en el contexto de la cultura nacional. Pervive en esta relativización el tono especulativo con el que Donoso imagina, ex situ, el país y la ciudad natal. Este mismo tono guía la percepción de Santiago, desnaturalizando las ideologías impuestas por "la oligarquía contemporánea que lleva las riendas de mi país y determina el rostro de mi ciudad" (209). Aludiendo en un primer momento a la fisonomía de la capital, este comentario deviene crítica al orden establecido que define un rostro, vale decir una identidad que, a diferencia de la máscara, no admite transformaciones sustanciales. Observamos aquí otra arista de la museificación que el autor relaciona con el empobrecimiento del pasado y las prácticas urbanas (Artículos 206). Conviene destacar que esta crítica, articulada en el extranjero, se realiza ahora con un sentido en el que "mi ciudad" comporta una cercanía con las prácticas urbanas y literarias de Santiago a través del oficio de la escritura.

En este encuentro in situ con la ciudad, el autor intenta dejar de lado el ansia de "absorber y comprender rápido", a fin de no "integrarse inmediatamente 
a una glotonería que resulta indigesta" (Artículos 205). Este apetito de absorber sin dilación se opone, como imagen de conocimiento que absolutiza el espacio, a la exploración pausada y equívoca en elaboraciones paisajistas que se sobreponen al imperio de la visualidad por medio de otros ámbitos perceptuales. Incluso los efectos sinestésicos, sujetos a la presencia de los estímulos, se entrelazan con el flujo de visiones provenientes de la imaginación. Donoso se debate así entre dos formas de habitar la ciudad. Una de corte omnímodo que busca gobernar el complejo tejido urbano; otra parcial y tentativa que encarece las "prerrogativas del novelista: observar, escuchar, preguntar para permitir que Santiago me vaya invadiendo, y suscite fantasías" (204). Se suma a estos modos la experiencia locomotora del caminar. Central en las rutinas del autor, esta circunstancia de enunciación permite la (im) presión táctil y directa de los espacios urbanos ${ }^{6}$. Posteriormente, el encuentro en cuerpo vivido con Santiago deriva en la cartografía de otro espacio, el cronístico. Desde aquí, la enunciación literaria de Santiago altera la solidez de los referentes con la voz de una subjetividad que explora sus propias filias y fobias a medida que transita la ciudad.

El redescubrimiento de la ciudad natal se presenta, en sus palabras, "como una situación límite para sus nervios y capacidad de adaptación” (Artículos 204). Sus recorridos delatan una relación tensionada con el paisaje urbano, cuya fragilidad remite al cronista a su propia situación existencial. "En este primer momento del reencuentro resulta dificilísimo recuperar la ligazón afectiva por esa ciudad que uno tenía metida adentro, ciudad que ahora no existe" (Artículos 205). Santiago gozó, por lo tanto, el carácter de un paisaje interior e interiorizado por los afectos. Destacamos que este desconcierto afectivo sobrepasa límites citadinos. Fragmentos de diarios escritos durante este período demuestran que esta crisis engloba toda su sensibilidad. "Asumir la estrechez de mi mundo pasional -en la que no dudo que no hay mucho de miedo-no es novedad para mí" (Diarios 498), admite el autor en reflexiones que acentúan un vacío desde el cual, no obstante, "nacen mis libros, donde se encuentra la raíz de mi fantasía" (498). Ahora bien, en sus crónicas, Donoso manifiesta una adhesión con la ciudad de "piedra, historia y barro de la realidad"

\footnotetext{
"Las animitas: un culto del pueblo" (1963) ilustra tempranamente "la lectura del espacio urbano a través del recorrido, es decir, por medio de una circunstancia sensible de enunciación. [...]. En efecto, a diferencia de otras crónicas en las que el espacio se circunscribe a un par de calles o a un barrio, [Donoso] finalmente abre el plano de la ciudad gracias a la ubicuidad de las animitas" (Ferrada, "Construcción" 72).
} 
(Artículos 116), pero sobre todo una "ligazón" imaginativa con sus espacios y sujetos urbanos. "El 'contacto' - la contigüidad, la fricción, el encuentro y la colisión- es la modalidad fundamental del afecto" (Comunidad 51), confirma Jean-Luc Nancy, proyectando el cuerpo a un lugar político-afectivo cuya significación, en el ámbito de las crónicas, se consolida con el espaciamiento de la fantasía literaria. Esta suerte de diseminación contradice la modelación de un sujeto cartesiano autónomo y "desafectado" del mundo circundante.

Esta ligazón sugiere una corporalidad que respira metafóricamente, y como experiencia emotiva desde la cual el sujeto de la enunciación se reintegra a Santiago desde la fantasía. La constitución del paisaje delata así un preámbulo dérmico y, desde aquí, la comparecencia del entorno ante un sujeto que ejerce el derecho a fantasear, transformando la materialidad de los espacios en paisaje literario. Esta coyuntura abre la posibilidad de visualizar a Donoso como autor de obras paisajistas, en particular cuando reconoce la impresión estética que los paisajes efectúan en su sensibilidad, y como constatan las crónicas analizadas en este estudio. El diseño narrativo de El lugar sin límites, El obsceno pájaro de la noche, La desesperanza o El Mocho depende, en gran medida, de paisajes en torno a imaginarios constitutivos del valle central y del sur de Chile ${ }^{7}$. Aun así, Donoso pareciera no advertir la inflexión que los paisajes producen en sus crónicas, texturizando y problematizando las cartografías oficiales que museifican la ciudad.

Lo impremeditado, aquello que sobrepasa el arte de la ficción, es un tópico recurrente en las reflexiones de Donoso. Sobre este punto ha dicho que no le "interesan los escritores que llegan a una conclusión antes de su obra y construyen una ficción para exponerla" (Diarios 161). En entrevista de 1987, durante la Feria Internacional del Libro en Buenos Aires, declara, en tono similar: "Los escritores somos muy mentirosos, y mentimos mucho sobre nuestras propias obras, de las que no entendemos nada, absolutamente nada. No sabemos ver nuestra obra" (Cit. en Giardinelli 5). Y, advertimos, tampoco las composiciones paisajistas que dibuja su escritura a medida que ésta recorre el cuerpo de la ciudad. Percibida en una instancia preliminar de afectación física y locomotora, la ciudad es abstraída en sucesivos actos de traducción

\footnotetext{
En un fragmento de sus diarios personales, el autor reflexiona sobre el papel que ha jugado el paisaje en la configuración de la narrativa contemporánea, concluyendo que "al fin y al cabo, la tradición esencial, o radical (en cuanto a raíz) de la novela latinoamericana es la novela paisajística" (Cuaderno 53, Santiago, 19 de agosto de 1981).
} 
literaria. Esta autoría es motivada por una experiencia en la que habitar el mundo equivale a estar en el paisaje (Besse, Sombra 163). Así, las crónicas movilizan un sujeto de la enunciación que construye y se deja construir por el paisaje. Este juego de retraimiento e imbricación desactiva el pensamiento paisajista antropocéntrico que se verifica en los discursos iluministas. En lugar de protagonizar la elaboración del paisaje autónomamente, y desde un prisma cartesiano, las crónicas crean un espacio de reciprocidad en el que el cronista y el paisaje, ambos en condición de devenir, se transforman intercambiando imágenes y saberes.

"El retorno del nativo" evoca, entre otras, imágenes en sintonía con la modernización de la capital. "Ciertamente, por lo menos por el momento; comprendo que el tiempo puede cambiarme -con este Santiago de letreros de cartón y plástico, este novelista no logra enchufarse emocionalmente" (207). La ciudad y el país entran en relación metonímica, y se asemejan a un tablero de circuitos fijos. La figura de una red eléctrica es análoga a la cuadrícula de las ciudades latinoamericanas, que operó como "metáfora del poder centralizador" (Guerra 41-42). Pese a notables diferencias de corte histórico, persiste en estas tramas la voluntad de gobernar el territorio geométricamente, a expensas de otras formas descentradas, como el espaciamiento de la subjetividad a través de fantasías e impresiones paisajistas a partir del contacto en cuerpo vivido con la ciudad. Tanto la ansiedad de gobernar como de imaginar conllevan una acción en el sentido original del pagus: abstraer un espacio y convertirlo en recurso disponible a nuestra voluntad. La distinción, sin embargo, recae en el tipo de abstracción. Mientras la "glotonería" de los estrategas piensa Santiago con el fin de jerarquizarla -la "zonificación" urbanística sería uno de sus dispositivos-, las prerrogativas literarias desactivan las narraciones homogéneas de la ciudad, ofreciendo afluentes insospechados para su percepción y habitabilidad.

La metáfora de la glotonería es consistente con las apreciaciones sobre la cultura nacional en las crónicas del autor. Esmerados en censurar la disidencia, los estrategas reifican las "huellas de nuestro modesto pasado [...], ahogadas dentro de un contexto político-económico-social que las aplastan, o las museifican con el pretexto de conservarlas" (Artículos 20607). El ejercicio de un poder institucionalizado sustituye así el dinamismo urbano por un dominio paralizante. Se añade una lógica de consumo donde el espacio, siguiendo la alusión a la glotonería, se somete a un vaciamiento despiadado que recuerda la depredación del paisaje que Donoso advierte en "Tener y no tener". La amplitud del territorio en aquella crónica converge en 
"El retorno del nativo" en la noción de país, por un lado, y de un paisaje con rúbrica urbana. Aparece así un paisaje vaciado de sus entrañas y devorado rutinariamente. La nostalgia por la ciudad desde Europa se acrecienta in situ. La proximidad con Santiago recrudece la sensación de lejanía y, como contrapartida, el anhelo de recuperar un paisaje entrañable.

"[P]aseando muy lento, recibo el primer y más elemental choque con la nueva realidad: me siento perdido en esta capital que abandoné cuando tenía poco más de dos millones de habitantes" (205). La ciudad habita, en este sentido, al menos dos interiores: el de las entrañas y el de la memoria, es decir en espacios donde el afecto se nutre tanto instintiva como culturalmente. En "El retorno del nativo" la ciudad y la subjetividad del autor se afectan en un dialogo de reciprocidades que origina la constitución, al tiempo visceral y "entrañable", del paisaje urbano. El autor insiste, sin embargo, en no dejarse llevar por la nostalgia, "no arrebatarse con decisiones y opiniones y posiciones irreversibles" (204). El peligro de la nostalgia es, por cierto, el arrebato de esencializar el pasado, similar a las estrategias de museificación. Con ello, el sujeto renunciaría a sus prácticas de resistencia, convirtiéndose en "instrumento de la clase dominante" (Benjamin, Discursos 178). La advertencia del autor vincula, en principio, la incapacidad de indagar el espacio urbano y político con el arrebato que aturde el sano juicio cuando se come en abundancia.

Arrebatar también significa "cocerse mal y precipitadamente por exceso de fuego" ( $R A E)$, hecho que denota falta de mesura. La misma ciudad se ha convertido en una "esponja ávida que ha ido dejando despoblado el resto del inmenso país" (Artículos 205). Trabajando con imágenes alusivas a un apetito visceral, Donoso favorece un descubrimiento tentativo de la ciudad, una recopilación pausada de impresiones sensibles que deriva en la construcción del paisaje urbano. Una de estas impresiones alude a sentirse perdido en la ciudad. Este extravío, sin embargo, no acusa conocimiento amoroso, sino imposibilidad de "enchufarse pasionalmente" con los espacios urbanos (207). Esto explica su identificación con Rayuela de Julio Cortázar, Sobre héroes y tumbas de Ernesto Sábato y La bahía del silencio de Eduardo Mallea, novelas en las que el protagonista está "inmerso, o como perdido en la ciudad, buscando o esperando al personaje femenino, [...] que será la Ariadna que los hará conocer, relacionarse con, prevalecer sobre, el laberinto de la ciudad, ya que ella lo conoce y es el símbolo de esa relación pasional" (208). Donoso mismo se pregunta, "un poco desesperadamente", si habrá una Ariadna en Santiago, quizás sin notar las cercanías entre la mítica figura y las fantasías que ha evocado. Ambas ofrecen hilos de un tejido, indicios que permiten 
habilitar la ciudad en la escritura. Propician, en otras palabras, un espacio literario que despliega variantes afectivas para un paisaje urbano iterativo.

En "El espacio literario", Donoso celebra a "autores que han creado ciudades inolvidables con palabras, ciudades que son más ciudades y más emocionantes que las ciudades de piedra, historia y barro de la realidad, y a veces más eternas" (Artículos 116). Si bien destaca el trabajo de novelistas, los registros paisajistas en sus crónicas comparten la misma renovación transformadora que anima, por ejemplo, "el París nocturno y cargado de amenaza de Víctor Hugo en Los miserables" (116). Las carencias que el autor lamenta en Santiago acentúan un paisaje "horadado" por edificios y galerías similares a "un queso gruyere y parecen ser lo característico de nuestra nueva arquitectura urbana" (207). Se suprimen los límites, y "una increíble variedad de anuncios lo borronean todo" (207). En esta acotación, Donoso subraya una yuxtaposición de formas y funciones, rasgo paradigmático de la arquitectura postmoderna ${ }^{8}$. Pero el comentario apunta, de modo más acuciante, a la dificultad de distinguir los elementos de una composición. Irrumpe así un espacio indiferenciado que se descompone en secuencias uniformes desprovistas de relieve. La proliferación de anuncios recuerda, "como tantas cosas en las ciudades y en el paisaje y en las carreteras chilenas, a Marruecos, a los zocos cubiertos de Fez y Mekne" (207). Estos signos urbanos se unen a la homogeneidad cultural y delatan, a fin de cuentas, un paisaje borrado 9

Cuando el centro de la ciudad ocluye la percepción de formas heterogéneas $\mathrm{y}$, desde un punto de vista ontológico, la posibilidad de enmascarar la identidad, Donoso opta por otros espacios. "[E]n mi afán de volver a relacionarme con esta ciudad, que es la mía, y que tan porfiadamente se me escapa de las manos, después de veinte o más años de no verlos he vuelto a recorrer minuciosamente

\footnotetext{
Desde sus impresiones, Donoso anticipa una noción que Fredric Jameson articula en 1991 sobre el Hotel Bonaventure de Los Angeles. "Aun no poseemos el equipamiento perceptual que se acomode a este nuevo hiperespacio [...] debido a que nuestros hábitos se formaron bajo ese espacio anterior que vinculo al modernismo" (37-38, traducción mía), sostiene el autor. La falta de sincronía entre las mutaciones del espacio postmoderno y los sujetos que lo productivizan es, en la esfera de la arquitectura, análoga al desconcierto que Donoso experimenta ante el paisaje horadado de Santiago.

9 Sobre este aspecto, ver "La homogeneidad nacional" (1985) y "País 'desinflado"" (1987) en José Donoso. Diarios, ensayos, crónicas, y "La libertad y el lirismo" (1988) en Artículos de incierta necesidad. En una breve crónica, "Paisaje borrado", Donoso estima que la cordillera se ha vuelto opaca y sin transparencia, metáfora geológica de la condición política y social de Chile en la década del ochenta.
} 
los Barrios Bajos de Santiago" (Diarios 302). La subjetividad del cronista dibuja una cartografía en la que el espacio se abstrae y deviene paisaje que asemeja la autonomía de una isla, "que queda de la Carretera Panamericana hacia el Oriente hasta la Quinta Normal, desde Rozas hasta el Club Hípico y el Parque Cousiño, una especie de isla en otro tiempo opulenta que se va deteriorando tranquilamente" (302). El espacio planificado desde la urbanística obedece coordenadas que la enunciación literaria reconfigura y amplifica continuamente. La conexión de este espacio con el resto de la gran ciudad se disuelve en una deriva que da paso, vía metafórica, a un paisaje urbano insular. Alentado por la figura de una isla, este diseño paisajista desajusta los barrios en más de un sentido.

Por un lado, las áreas tradicionales se desprenden de las transformaciones del centro de Santiago, alcanzando un carácter independiente en virtud de su anacronismo. Los barrios bajos se escinden, cual islas, de un continente hecho de "letreros de cartón y plástico" (Artículos 207). Esta separación geográfica confirma distancias socio-culturales y confrontaciones disímiles de la modernidad al interior de la misma ciudad:

Esta modestia, por no decir pobreza e incluso miseria, distinta a las bullentes poblaciones obreras de más al oriente y al norte y al sur, es hoy la contradicción misma de las multinacionales de acero y cristal, y de los shopping centers del Barrio Alto, idénticos a cualquier ciudad del medioeste de USA donde ahora vive de una manera muy distinta la gran burguesía y la clase media de Chile (Diarios 302-03).

En este contexto de relaciones divergentes sobresale un carácter periférico que no difiere sustancialmente de los paisajes que el autor percibe en "Música condenada a morir", "Arte y magia del vidrio" y "Las animitas: un culto del pueblo". En estas crónicas de 1963 "los barrios santiaguinos integran un margen que incide en la construcción de espacios y subjetividades, es decir, en la postura que se adopta para retratar el paisaje urbano" (Ferrada, "Construcción" 72) y, añadimos, sus diversos niveles de modernización. No obstante, la distinción entre la mirada paisajista en las crónicas del sesenta y del ochenta sobreviene con la incorporación decidida del autor a espacios que configuran su subjetividad.

Por otro lado, y a diferencia de la ciudad ex situ en "Tener y no tener" o los espacios fragmentados en "El retorno del nativo", es en los barrios bajos donde la fantasía y los hilos de Ariadna se insinúan con mayor vigor. "Estos paseos míos," concede Donoso, "como la petite madeleine proustiana, 
evocaron toda clase de sensaciones, toda mi niñez [...] transcurrida en una profunda casa crepuscular de tres patios en la calle Ejército, fragante de confites de nombres olvidados puestos a enfriar en el mármol enmantequillado de una mesa de la galería de las aspidistras" (Diarios 303). A diferencia de los paseos erráticos por el centro de Santiago, transitar los barrios instancia un paisaje reminiscente afín con las fantasías que ahora abrazan al cronista. Donoso enfatiza los "pintoresquismos de otra época" (302), vinculados a un imaginario de prácticas cívicas en el que, por ejemplo, era frecuente ver para 18 de septiembre al "Presidente de la República con sus Ministros [...] pasando por nuestra calle desde cuyos balcones se les vitoreaba" (304). Avanzar aquí es retroceder, cediendo la vivencia del cuerpo a un paisaje extemporáneo y fluido donde el autor deja de ser "extranjero en su propio país y en su propio idioma" (Artículos 218). La construcción paisajista del entorno urbano coincide así con la imaginación de la ciudad en "El espacio literario", ciudad que "vive y duele e invade el texto con su pasión e inexactitudes y limitaciones" (116).

Antes señalamos que Donoso parece no advertir las huellas paisajistas que se deslizan en sus crónicas. Sin embargo, es consciente de la alteración que produce su escritura, que avanza a contracorriente en un género comprometido con la actualidad. "Nada puede ser menos contemporáneo, menos trascendente en el momento que la historia ahora vive, que esto que estoy escribiendo, y nada menos 'importante"” (Diarios 303). A partir de la experiencia sensible del cuerpo con la ciudad, surge un paisaje que migra de la visualidad y contingencia de los referentes urbanos hacia la subjetividad del cronista. Las rutinas domésticas en la casa de calle Ejército tampoco tuvieron transcendencia en la década del treinta, "tiempos de la Milicia Republicana y de la Guerra Civil Española, del retorno de Europa de la parentela que vivía allá y fue tan astuta como para ver el vendaval que venía [...]" (303). Como sus parientes, Donoso también supo predecir vendavales, en este caso el que consumiría a Chile en los ochenta, y que le hiciera escribir desde España: "Habrá toques de queda, razzias, vigilancia, listas negras. [...]. El silencio será lo peor para mí, y no se hablará de otra cosa que de política" (Cuaderno 52, Madrid, 16 de julio de 1980). Pese a todo, el nativo regresa al país y opta, como hace en "Los barrios bajos de Santiago", por hablar de otras cosas que de política. Aun así, la petite madeleine, como los confites criollos, evocan una infancia rodeada de certezas que remite, por efecto de contraste, a la degradada condición política y cultural del país. La fragancia de estos dulces despierta, en efecto, un apetito político que se sacia en una 
crítica a la homogeneidad que los estrategas imponen sobre la ciudad. Cuando discute la arquitectura del barrio, el autor señala:

En todo caso en ninguna de esas mansiones de tabiquería y mármol simulado, ahora subdivididas, en esas callejuelas torcidas alrededor del antiguo Teatro Carrera, en ninguna, digo, falta la televisión: de modo que esa gente debe ser exactamente igual, y sus ideas y conversaciones muy parecidas a la arrogante gente que habita los beaux quartiers del Barrio Alto (303-04).

Si bien el barrio de su infancia lo conecta excepcionalmente con fantasías que la ciudad en "El retorno del nativo" le niega, este mismo espacio insular ha adoptado, en el presente de la enunciación, prácticas que impiden conjugar otra variedad de máscaras. La imagen televisiva, percepción catatónica del mundo, opera en dirección opuesta a la posibilidad estético-afectiva de constituir un paisaje en "cuerpo vivido". Revela la instalación de una uniformidad que anula trayectorias heterogéneas y descentradas sobre el paisaje. "Esta similitud de pensamiento es una decepción para mi deseo de reencontrar el mundo estático del tiempo de mi niñez" (304), acota Donoso. Interpretamos ese mundo a la luz de una crítica benjaminiana. Su quietud advierte una solidez burguesa que busca "insularse" del vendaval de la historia (Discursos 180), impidiendo que las ruinas del progreso invadan la casa crepuscular. Notables transformaciones ya remitían la ciudad de Santiago de aquella época a un proyecto modernizador irrenunciable. El placer de ese mundo yace, paradojalmente, en su inmunidad, en su capacidad de retraerse de todo aquello que, a fin de cuentas, delate su frágil estructura.

Si inicialmente la ciudad encarece la mirada perpleja del cronista, en los "barrios bajos" el nativo intentará recuperar la ciudad "que tenía metida dentro", articulando un paisaje insular que lleva la enunciación al mundo de la niñez. Siguiendo el pensamiento de una geografía humanista, Besse considera que "el paisaje no es un lugar cerrado sobre sí mismo, sino lo que abre la mirada hacia otra parte, hacia algo inacabado que es propiamente apertura del sentido y de la historia y no clausura sobre el genio del lugar" (Sombra 168). La subjetividad de Donoso y los paisajes que percibe se proyectan, ciertamente, hacia otro espacio que, atendiendo al contexto político y biográfico de la enunciación, podría calificarse de utópico. "Pasear por la calle Ejército, hoy, es ponerme en contacto a través del recuerdo de una anciana encamada, y casi tocar toda la cultura y la historia que me ha formado" (306). Se suspenden los hitos tangibles del entorno, como la arquitectura laberíntica del centro 
de Santiago o la materialidad de las habitaciones en calle Ejército. Emerge, en cambio, el no-lugar de un paisaje "insulado" en la subjetividad del autor, paisaje que se desprende de la relación en cuerpo vivido con la ciudad y encuentra su espacio literario en el corpus de las crónicas.

\section{CONCLUSIONES}

Este trabajo ha abordado una selección de crónicas y fragmentos de diarios personales de José Donoso que evidencian la emergencia de un paisaje urbano en cuerpo vivido, es decir desde relaciones sensibles con la ciudad de Santiago. Este vínculo, o ligazón, se insinúa ex situ desde escritos producidos en el extranjero, pero alcanza solidez literaria in situ tan pronto Donoso se reconecta con los espacios de su ciudad natal. Al concluir este trabajo, percibimos que la relación corporal y afectiva con la ciudad actúa como preámbulo para la configuración de otro paisaje, subjetivado e insular. El paisaje se encuentra así sometido a un constante desplazamiento, a una poética o "consciencia estética de que todo arte es, en parte, artificio" (Donoso, Artículos 457) que acentúa las prerrogativas y fantasías del autor. Bajo esta perspectiva, la mirada de Donoso sobre el entorno se proyecta más allá de la producción efectiva de las prácticas urbanas. En el ámbito textual, esta proyección favorece diversas relaciones metonímicas, como la confrontación en "El retorno del nativo" de un almacén de cinco pisos y la iglesia de San Francisco, "que no deja de tener cierto airecillo de metáfora" (Artículos 207). En el ámbito biográfico, esta mirada permite al autor leer los hitos urbanos como signos de un orden político y modernizador que desafía su incorporación imaginativa a la ciudad de Santiago.

En una edad en la que no parece "enchufarse" con la ciudad, Donoso se embarca en otro viaje que lo conduce a "esa especie de isla" que son los barrios bajos, donde legitima una relación corporal y reminiscente con la ciudad. Apreciamos, por lo tanto, la emergencia del paisaje en el extranjero con las especulaciones del autor, para continuar in situ en las áreas céntricas de la ciudad y decantar finalmente en la deriva geográfica y social de los barrios bajos. Este desplazamiento delata cómo el paisaje se interioriza gradualmente, al punto de alojarse en la subjetividad y fantasías del autor. En lugar de proyectarse externa y visualmente, el paisaje se incorpora a una poética escritural del autor. El barrio de su infancia conforma un espacio complejo, asociado a un modus vivendi tradicional $\mathrm{y}$, hasta cierto punto, 
imperturbable, y a cambios que normativizan la convivencia. Por un lado, los barrios suscitan fantasías para la constitución de un paisaje urbano afectado, principalmente, por las prerrogativas del escritor. Por otro, estas fantasías no encuentran asidero en las condiciones del tiempo presente, sino en imágenes pretéritas. Los recorridos por Santiago sugieren la migración desde un "continente" a una "isla", y con ello una apertura crítica y literaria derivada de este desplazamiento.

Lo que está en disputa, desde luego, es la crítica a una modernidad que intenta uniformar las prácticas urbanas. La advertencia al mundo televisado es signo de esta homogeneización que impide experimentar la diferencia y la otredad. En el marco de nuestro trabajo, esta disposición al vacío es doblemente acuciante. Admite que los recorridos de Donoso por la ciudad surgen no solo biográficamente, sino como parte de un registro paisajista que les confiere un carácter estético. Y por otra parte, esta indeterminación libera al autor de convertirse en "una sola 'persona' esclavizadora" (Pilar Donoso 253), tan pronto el cuerpo se pierde y desaparece en una comunidad de otros cuerpos que también anhelan máscaras. “¿Por qué indicios en lugar de signos distintivos?", pregunta Nancy. "Porque el cuerpo escapa, nunca está asegurado, se deja presumir pero no identificar" (Indicios 26).

¿Iríamos muy lejos si sugerimos que, además del paisaje urbano, anima las crónicas un paisaje emotivo cuyo principal referente es la propia subjetividad del escritor? ¿O es que una paisajística urbana, y su aparición en el cuerpo de la escritura, comprometen ya todo un acervo emocional y expresivo? La construcción de un paisaje insular, enraizado en la afectividad de los recuerdos, configura un espacio excepcional que refrenda el carácter literario de las crónicas. El paisaje en la escritura tiende a mostrarse en consonancia con la búsqueda de una Ariadna, un modo de expresión que transforma una exterioridad, la laberíntica e inabordable ciudad de Santiago, en una interioridad, que en las crónicas estudiadas se encarna en el paisaje insular de los barrios. El retorno del nativo constituye así un hito biográfico tan crítico como su exilio, y de aristas contextuales que estimulan el descentramiento de la identidad, la posibilidad de escribir sobre "intrascendentes" casas crepusculares y el esbozo de una poética paisajista. Es en esta última esfera donde las crónicas de José Donoso desdibujan el "rostro" (Artículos 209) uniforme que la oligarquía contemporánea impone sobre su ciudad, reemplazándolo por enmascaramientos y fantasías literarias. 


\section{BIBLIOGRAFÍA}

Benjamin, Walter. Discursos interrumpidos I. Filosofia del arte y de la historia. Madrid: Taurus, 1989.

Besse, Jean-Marc. La sombra de las cosas. Sobre paisaje y geografía. Madrid: Biblioteca Nueva, 2010.

"El espacio del paisaje". III Jornadas del Doctorado en Geografía, 29 y 30 de septiembre de 2010, La Plata, Argentina. Recuperado de: http://www.memoria.fahce. unlp.edu.ar/trab_eventos/ev.1488/ev.1488.pdf.

Campra, Rosalba. América Latina: la identidad y la máscara. Madrid: Siglo XXI, 1987.

Catalán, Pablo. Cartografía de José Donoso. Un juego de espacios. Un arte de los límites. Santiago: Frasis Editores, 2004.

De Certeau, Michel. La invención de lo cotidiano I: Artes de hacer. México, D. F.: Universidad Iberoamericana, 2007.

Donoso, José. Artículos de incierta necesidad. Ed. Cecilia García Huidobro. Santiago: Alfaguara, 1998.

Conjeturas sobre la memoria de mi tribu. Santiago: Alfaguara, 1996.

Historia personal del "boom”. Santiago: Alfaguara, 1998.

José Donoso: Diarios, ensayos, crónicas. Ed. Patricia Rubio. Santiago: RIL Editores, 2009.

Cuaderno 52. Julio 1980-Mayo 1981. José Donoso Papers. Box 59, Folder 1. Manuscripts Division, Department of Rare Books and Special Collections, Princeton University Library.

Cuaderno 53. Julio-Diciembre 1981. José Donoso Papers. Box 59, Folder 2. Manuscripts Division, Department of Rare Books and Special Collections, Princeton University Library.

Donoso, Pilar. Correr el tupido velo. Santiago: Alfaguara, 2009.

Ferrada Aguilar, Andrés. "Articulación de una poética para la ciudad enmudecida en las crónicas de José Donoso”. Revista Chilena de Literatura 87 (2014) 115-138.

"La construcción marginal de Santiago en las crónicas de José Donoso". Anales de Literatura Chilena. Facultad de Letras, Pontificia Universidad Católica de Chile. $\mathrm{N}^{\circ}$ 25, 2016. 55-79.

García Canclini, Néstor. Imaginarios urbanos. Buenos Aires: Eudeba, 2010.

Giardinelli, Mempo. "José Donoso: sobre cuentos y novelas". Entrevista en Revista Puro Cuento $\mathrm{N}^{\mathrm{o}}$ 5, julio/agosto 1987. Recuperado de: https://estoespurocuento.wordpress. com/2013/05/28/jose-donoso-sobre-cuentos-y-novelas-entrvista-por-mempo-giardinelli/

Guerra, Lucía. Ciudad, género e imaginarios urbanos en la narrativa latinoamericana. Santiago: Editorial Cuarto Propio, 2014.

Jameson, Fredric. Postmodernism, Or The Cultural Logic of Late Capitalism. Durham: Duke UP, 1991. 
Lefebvre, Henri. La producción del espacio. Madrid: Capitán Swing Libros, 2013.

Maderuelo, Javier. "El paisaje urbano”. Estudios Geográficos Vol. LXXI, No. 269 (2010): 575-600.

Milani, Raffaele. El arte del paisaje. Madrid: Biblioteca Nueva, 2007.

Morales, Leonidas. De muertos y sobrevivientes. Narración chilena moderna. Santiago: Cuarto Propio, 2008.

La escritura de al lado. Géneros referenciales. Santiago: Cuarto Propio, 2001.

Nancy, Jean-Luc. 58 indicios sobre el cuerpo. Extensión del alma. Buenos Aires: La Cebra, 2010. La ciudad a lo lejos. Buenos Aires: Manantial, 2013.

La comunidad enfrentada. Buenos Aires: La Cebra, 2007.

Schoennenbeck, Sebastián. José Donoso: paisajes, rutas y fugas. Santiago: Orjikh, 2015.

Sennett, Richard. Carne y piedra. El cuerpo y la ciudad en la civilización occidental. Madrid: Alianza, 2015. 